\title{
THE CULTIVATION OF THE TURBOT
}

From BULLETIN OF THE BUREAU OF FISHERIES, Volume XXVIII, 1908

Proceedings of the Fourth International Fishery Congress : : Washington, 1908

-

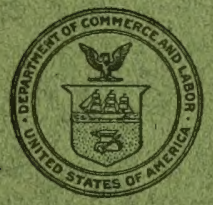

WASHINGTON : : : : : : GOVERNMEINT PRINTING OFFICE : : : : : : 1910 
$\gamma$ 



\section{THE CULTIVATION OF THE TURBOT}

From BULLETIN OF THE BUREAU OF FISHERIES, Volume XXVIII, I908

Proceedings of the Fourth International Fishery Congress : Washington, 19o8

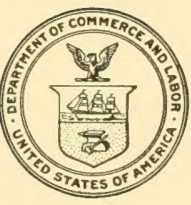

WASHINGTON : : : : : . GOVERNMENT PRINTING OFFICE $: \quad: \quad: \quad: \quad: 1910$ 


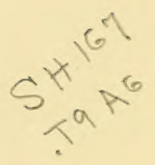

BUREAU OF FISHERIES DOCUMENT NO. 686

Issued April, 1910

$$
\begin{gathered}
\text { APR } 301910 \\
\text { Das Da }
\end{gathered}
$$




\title{
THE CULTIVATION OF THE TURBOT
}

\author{
By R. Anthony, D. Sc. \\ Assistant Director, Laboratory of the Museum of Natural History \\ (Paris) at St. Vaast-la-Hougue \\ Paper presented before the Fourth International Fishery Congress \\ held at Washington, U. S. A., September 22 to 26, 1908
}





\title{
THE CULTIVATION OF THE TURBOT.
}

\author{
* \\ By R. ANTHONY, D. Sc., \\ Assistant Director, Laboratory of the Museum of Natural History (Paris) at St. Vaast-la-Hougue.
}

[Translated from the French.]

The question of marine pisciculture has been for some thirty years a subject of important concern to naturalists. The present crisis in marine fisheries and the necessities involved seem to cause an increase of efforts in this direction.

The term marine pisciculture serves to designate either natural pisciculture or artificial pisciculture (piscifacture), both public and private or industrial.

The so-called natural pisciculture is the simple operation of making the young edible fishes hatched at sea enter marine ponds or artificial reservoirs communicating with the sea, there to be fattened and then captured for market when they have attained a commercial size. Practiced for centuries, its development did not demand any previous knowledge of the phenomenon of reproduction of the fishes. But it does demand the realization of natural conditions which are very special as to localities and surroundings, a thing which prevents it from becoming general.

To this pisciculture, rudimentary to a certain extent, may be opposed the so-called artificial pisciculture, or piscifacture, thus named because the eggs and larvæ are obtained in captivity.

Artificial pisciculture may pursue either of two aims: It may be a public enterprise, an undertaking of the government, as a government alone can enter upon such an operation, its aim then the repopulation of the sea; on the other hand, it may be a strictly private enterprise to inaugurate an industry which would pursue the aim of breeding certain edible sea fishes in captivity for profit.

The first attempts at artificial pisciculture were public undertakings; the aim was to attain the breeding of edible shore fishes in captivity, to have the eggs hatch, and to deposit the larvæ at a point on the coast where a decrease of these fishes had been noticed. The young fishes were released in the sea 
a few days after they were hatched, before the entire disappearance of the yolk sac and the beginning of feeding by external means. The Government of the United States was the first to interest itself in this question of such important general concern, by founding in I8 78 at Gloucester, in the state of Massachusetts, in the vicinity of the great city of Boston, the first public establishment for marine pisciculture. The establishment at Gloucester was soon followed by one at Provincetown, one at Woods Hole, and one on the steamer Fish Hawk. In 1883 Norway followed the example of the United States and created the establishment of pisciculture at Flödevig. In 1889 the Government of Newfoundland founded the establishment of Dildo and, lastly, in I894, Great Britain founded, thanks to the Fishery Board of Scotland, the establishment of Dunbar. These various establishments gave each year to the sea several thousands of cod, plaice, and even turbots, hatched in captivity; it must nevertheless be said that it was never possible to obtain at Dunbar, the only establishment where the replenishing of coastal waters with turbots was attempted, any natural hatching of this fish, and that it was always necessary to have recourse to artificial stripping and fertilization as practiced for the fresh-water fishes.

It is not our aim to discuss, after so many others have done so, the question of the real utility of marine pisciculture for the replenishment of the sea. Let us merely remember from the experiments of our predecessors this very important fact: It is due to their efforts that at the present time we have been able to obtain natural spawning in captivity and the hatching of eggs of the greater number of edible coastal fishes having pelagic eggs.

For some twelve years French naturalists seem to have devoted themselves to private or industrial artificial pisciculture. In other words, the work done to-day is an attempt at the entire process of breeding edible fishes from the egg until they reach a commercial size, to create thus a real industry which may in future become an actual source of riches. The first step in the new direction was made by Mr. Edmond Perrier, Director of the Museum of Natural History, Member of the Institute, and director of the maritime laboratory of St. Vaast-la-Hougue, who has the great merit of having been the first to appreciate the importance of the problem and to establish at his laboratory a complete equipment for industrial marine pisciculture.

It will be remembered that without any thought as to its industrial value and for purely scientific purposes, Meyer had been breeding the herring since I878; at Flödevig young cods were bred, at Plymouth young flounders, and at Concarneau young bullheads; at Dunbar, Harald Dannevig had succeeded in breeding young plaice. In addition to the fact that the industrial point of view was entirely overlooked in these experiments, species of small or no commercial value were experimented upon. 
Before attempting marine pisciculture it is necessary to ask oneself what are the fishes for which such experiments would be practically profitable. It is evident that migratory fishes, or those living in depths the natural conditions of which we can not offer them in captivity, are to be eliminated. Moreover, before attempting the breeding of nonmigratory fishes of commercial value there is a certain number of questions which ought to be answered: (I) Is the fish in question of sufficient commercial value to render its breeding profitable? (2) Is its growth in captivity sufficiently rapid, and is the cost of bringing it to its commercial size disproportionate to its market price?

In the last analysis it will appear that among the fishes inhabiting our European waters there are only four species which are profitable objects of marine pisciculture. These are the sole (Solea vulgaris Quensel), the turbot (Rhombus maximus Linnæus), the umbrina (Labrax lupus Cuvier), the surmullet (Mullus surmuletus Linnæus). According to Cunningham, the turbot at the age of two years is from 28 to 38 centimeters long, and reaches 60 centimeters at the age of four years. As to the sole, it reaches only 23 centimeters at the age of two years.

Of all these various edible fishes, the most profitable from the point of breeding is the turbot, on account of its high price, its particularly rapid growth, its prodigious fecundity (the turbot yields about 9,000,000 eggs per year) and, lastly, its hardiness and the ease with which it may be fed and fattened. Unfortunately, however, this species is the one the artificial reproduction of which presents the greatest difficulties, as was justly observed in 1905 by FabreDomergue and Biétrix, whose researches in this line go as far back as i896. ${ }^{a}$ It must be remembered that no natural hatching of turbot could be accomplished at Dunbar and recourse was had to artificial methods of stripping and fecundation, as for fresh-water fishes.

The problem of industrial marine pisciculture must necessarily traverse two stages before reaching complete realization-a preliminary and purely scientific stage, and a final and really practical stage.

The scientific success of the problem seems to consist in hatching a reasonable number of young fishes and keeping them in the laboratory beyond the critical stage. (As defined by Fabre-Domergue, the critical stage begins when the umbilical vesicle is entirely absorbed and the young fish begins to look for food among its surroundings.) Practical success consists in keeping a considerable number of fishes until they acquire such condition that the operation may be really remunerative. It is evident that before attempting the study of the second feature of this problem the first must be solved. It is only when the

a Fabre-Domergue and Biétrix: Le developpement de la sole, 1905. Travail du Laboratoire de Zoologie maritime de Concarrieau. 
first stage shall have been passed that it will be legitimate to inquire whether the results obtained in the laboratory may or may not be repeated on a larger scale, i. e., to practical purpose, with perhaps a somewhat different technique. Practical marine pisciculture, the origin of which does not date further back than twelve years, is as yet in its scientific period.

The two principal difficulties involved in the solution of the scientific problem are the following: (I) The obtaining in captivity of natural and normal hatches in as great numbers as might be desired, and the determination of the conditions of these hatches. (2) The feeding and the preservation of a reasonable number

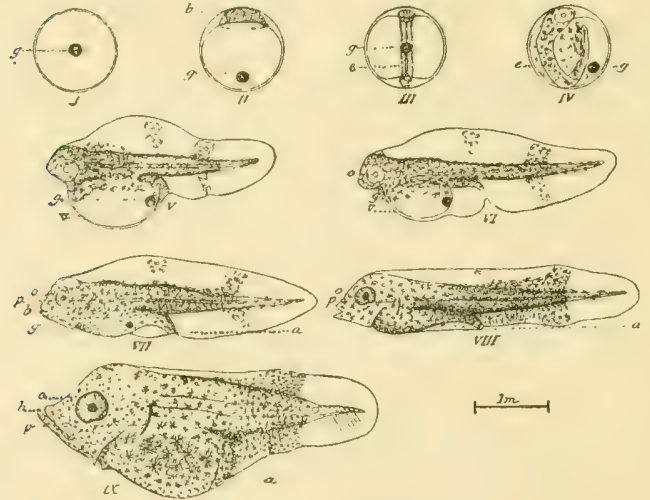

Fic. x.-Early development of the turbot.- $x$, Fecundated egg: II, egg with blastoderm: 11 , egg with embryo, not pigmented, IV, egg with pigmented embryo; v, larva just after hatching: vr, larva with vitel us about half resorbed: vil, larva with vitellus almost entircly resorbed vu, larva in critical period, vitellus just resorbed; $1 \mathrm{x}$, larva at end of critical period. $\theta$. Oil globule; $b$, blastoderm; $e$, embryo: $v$, vitellus; $b$, mouth; $a$, anus; 0 , eye; $p$, axis of insertion of pectoral fin. of larvæ beyond the critical period and under conditions such that the experiment may be repeated. As has been justly observed by Messrs. FabreDomergue and Biétrix (op. cit.), the incubation, hatching, and preservation of the larvæ until the beginning of the critical period do not present any difficulties.

In the laboratories of pisciculture in America, Norway, and England the question of hatching in captivity has been solved for the plaice and for the cod, but could not be solved for the turbot, the

only marine fish truly interesting from the point of industrial breeding. The passage through the critical period had not been attempted for any species in laboratories here cited, because the fishes were deposited in the sea before the beginning of this period. The principal object of practical marine pisciculture in recent years, then, in Europe at least, has been to obtain normal hatches of turbots in captivity and to carry their larvæ past the critical period.

It was at the laboratory of St. Vaast-la-Hougue that numerous normal hatches of turbots were obtained for the first time by A. E. Malard in $1898 .^{a}$

a Malard, A. E.: Sur le developpement et la pisciculture du turbot. Comptes rendus de l'Académie des Sciences, Paris, 17 juillet, 1899 . 
In I904, L. Dantan, ${ }^{\alpha}$ repeating these experiments, obtained an identical result at the same laboratory. In both cases the hatching took place normally, but unfortunately all the larva died a few days later, not being able to survive the critical stage. Thus only the first part of the problem was solved.

In 1905 Fabre-Domergue and Biétrix (op. cit.) published their memoir on the development of the sole. No hatches of turbot or sole could be obtained in the laboratory of Concarneau where these authors operated. FabreDomergue and Biétrix were obliged painstakingly to collect eyed eggs of the sole in the sea. But they were able to bring a small number of individuals far beyond the critical period. For the sole, at least, the second part of the scientific problem was realized. In 1905 Malard and Dantan, who had obtained normal hatches of the turbot, had not been able to carry their larvæ past the critical period, and Fabre-Domergue and Biétrix, who had not been able to obtain hatches, had carried the sole through the critical period. With the turbot, rearing past the critical period had not been accomplished.

In the course of 1907 we were more fortunate at the laboratory of St. Vaastla-Hougue than in 1898 and in 1904, and succeeded not only in making the larvæ live beyond the resorption of the umbilical sac, but in obtaining after this critical period a considerable increase of volume and an important modification of the shape. The conditions under which I obtained these results are the following:

During the month of February, 1907, I procured ro adult turbots, which I placed in the large hatching basins of the laiboratory. 'These basins, constructed according to the directions of Mr. Edmond Perrier, are three in number. The capacity of the largest is more than 300 cubic meters. They are filled by means of a pump, worked by a windmill, or a gasoline motor when the wind is not sufficiently strong. This pump brings the water to the upper part of the basin. A waste pipe is in the lower part. In the middle is an incomplete trench about the depth of a stair step, made after the design of A. E. Malard, to promote the spawning of the females, which this athor found rubled their abdomens against its acute angle. The basins are covered with a thatched roof and are amply lighted.

Let us note that so far there exists no certain external means of recognizing the sex of the turbots when alive, although many naturalists have endeavored to find it. Nevertheless, taking 12 individuals, there are great chances of having both females and males among them. The only thing to remember is that the fish should not be less than 40 centimeters in length. With smaller individuals there would be a risk of their not yet being mature.

a Dantan, L.: Notes ichthyologiques. Archives de Zoologie expérimentale et générale. Notes et revues, 1905 . 
At the end of a few weeks of captivity our prisoners began to feed. To them were distributed once a week large pieces of plaice at the rate of about half a fish the size of the hand to each turbot. This ration may seem scant, but it was purposely limited, we deeming that too great an abundance of food is not favorable to the functions of reproduction. It is probably to excess of feeding that must be attributed the failure of attempts to make the turbot spawn in captivity. In order to keep the basins free of putrefying food substances we put with our turbots a conger eel and a dogfish long since acclimated to life in captivity. These fishes, well known for their voracity, were employed as scavengers, in which capacity they did good service. Our turbots, in captivity since February, began to spawn in July.

We do not know yet whether individuals that have spawned in captivity and survived one season will spawn the following year. We will not know this until in July next. In any case it does not seem to us very important to know whether it is necessary to keep the same brood stock for one or more years, since fish captured only six months previously had ample time to get acclimated and have given excellent results. Let us add that it seems to us very imprudent to capture breeders only a few weeks before the spawning time. Not yet acclimated, they might exhibit phenomena of ovular retention, which are in most cases fatal.

The first eggs were laid on July is, and were soon followed by four other lots. The dates of the consecutive spawnings were July I 8, 21, 28, 29, and August 3. These lots of eggs numbered thousands and thousands, all normal and normally fertilized. A certain number only were carefully gathered by means of plankton nets and transferred to the incubation apparatus. An essential feature of this apparatus is continuous agitation, which is a very important thing in inculation, heeping the egg free of sediment and thus preventing asphyxiation. Dannevig, among others, at the station of Dunbar had already employed a complicated apparatus which provided continuous agitation.

The apparatus used by us was that of Fabre-Domergue and Biétrix modified, which apparatus is in itself a modification of that constructed by Browne at the laboratory of Plymouth to preserve pelagic organisms alive. It consisted of a receptacle in which a plunging disk rose and fell by means of a special contrivance. In the apparatus of Fabre-Domergue and Biétrix the somewhat violent agitation produced by the vertical motion of the disk is replaced by a helicoidal movement, the disk being obliquely fixed on a vertical rotating axis and thus working like a screw. The apparatus is composed of 4 glass barrels of 50 liters capacity, each supplied with a revolving disk, and the + disks are worked by a small hotair motor of $\frac{1}{40}$ horsepower. 
I thought it advisable to make a few modifications in the apparatus of Fabre-Domergue and Biétrix which seemed to me of great importance to the final success. On the thread of the vertical rod carrying the disk I attached above the level of the water, as tightly as possible, a small wad of absorbent cotton to take up and keep off the oil that might come from the wheels above it. I had observed that a small part of the oil could descend along this vertical glass rod and thus reach the water, where it formed a thin layer, the effect of which was hindrance of aeration, causing asphyxiation of the larve. Below this wad I placed, upside down, the disk-shaped cover of a small vessel, thus to keep dust from falling into the water, without, however, hindering the circulation of the air. This disk was secured below by a second wad of cotton. I also utilized the lower, lateral, tubular outlet of the barrel to set up a tube within terminating at the top in a funnel covered with very fine silk, to allow the passage of water but not of larvæ. The opening of this funnel was the size of a 5 -franc piece, and the flare thus obtained was designed to decrease, as far as possible, the intensity of the current, which, were it too violent, would certainly have carried the larva with it. This possible carrying out of the larvæ constitutes a real danger, against which, however, we are still better protected in the apparatus which we have had constructed for our experiments in 1908.

Several times a day part of the water in the barrel was renewed for Io minutes by means of a siphon, there being in the course of the supply tube a flaring inlet for the purpose of aeration.

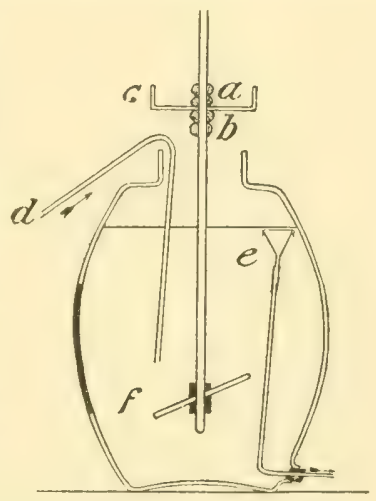

Frg. 2.-Apparatus for hatching turbot (modification of apparatus of FabreDomergue and Biétrix). $a$ aad $b$, wads of cotton: $c$, upturned cover which serves as dunt shicld, $d$, infirw pinc i, nut flow pipe with serecned fumelentrance, $f$, revolving disk for agitation of the water.

Several times a day also the bottoms of the basins were carefully siphoned to remove the dead eggs and all other matter that might pollute the water. These modifications, of details only, which we have made in the excellent apparatus in which Fabre-Domergue and Biétrix have been able to carry the sole past the critical stage ought to be considered an indication, so to speak, of more important modifications which will render possible its practical use on a larger scale than from the point of view of experiments only.

The hatching of the eggs took place without difficulty and without hindrance between the sixth and eighth days after spawning. Two or three days after the appearance of the larvæ, without waiting for the complete absorption of the 
yolk sac, and following in this the excellent advice given by Mr. Edmond Perrier in 1896 , at the Congress of Fisheries at Sables d'Olonne, and a little later, in Isgs, by Mr. Fabre-Domergue, we began the feeding of our young larvæ. Their diet was composed of live plankton collected in the open by means of fine-meshed nets, and carefully sifted upon arrival at the laboratory through very fine sifting silk, for the purpose of eliminating the organisms which night constitute a danger by their size or their nature. One distribution of plankton was made every day, and in great abundance. Moreover, the agitation of the water maintained the plankton alive, and the young fry had consequently always in reach a fresh live food as varied as under natural conditions of their life. Toward the fourteenth or fifteenth days the last trace of the sac disappeared, and about the eighteenth or twentieth day the critical period might be considered as passed. The young larvæ had at that period taken the peculiar shape characterized by the widening of the head, and they fed normally.

For the retention of the larvx after the beginning of the resorption of the yolk sac, i. e., during the critical stage, two things are necessary: (1) Continuous agitation of the water, and (2) appropriate food. Continuous agitation of the water is incontestably very useful in the incubation of the eggs and the normal life of the larva up to the time when they begin to feed, but during these periods it is not, as later, absolutely indispensable.

We have, in fact, found at St. Vaast, on the one hand, that the eggs which were left in our hatching basins developed there and hatched normally, and the larvæ did very well until after the disappearance of the yolk sac; on the other hand, the same facts were observed in the hatching aquaria. But what we did not accomplish, and we can not insist too much on this point, was to make larva live even a few hours, though offering them plankton, under these conditions after the disappearance of their yolk sac. It is at this time, we believe, with all who have undertaken marine pisciculture, that continuous agitation of the water is absolutely necessary. Without it the young fish is never in the presence of its food, it weakens, falls to the bottom, and dies of hunger.

As to feeding, let us recall that the fry were very precocious, and began to feed even before the complete disappearance of the yolk sac. The objection might be raised that plankton as the basis of food for the larve can not be considered for a moment where breeding on a large scale is to be undertaken. It may be said that on certain days storms disturb the sea, and the water being full of ooze and sand, collecting is impossible. We believe that we can say that the period during which plankton will be necessary is precisely during the season of the year in which storms are most rare (from July I to September I5, at the latest, for the region of St. Vaast-la-Hougue). Should there be storms, 
however, one would always have the resource of small plankton organisms in the pools left when the sea recedes. Moreover, the continuous agitation apparatus will allow us to keep alive a small reserve of plankton to supply the needs of our larvæ for three to four days. And, lastly, one more argument, shall it be considered a priori impossible to breed certain plankton organisms, carefully selected? Continuous agitation apparatus would undoubtedly be suitable for this purpose likewise. The experiments of Bracque have almost solved this question already. I am not opposed a priori to a semiartificial food as, for example, the Monas dunali of marshes successfully employed by Messrs. FabreDomergue and Biétrix for feeding their larvæ of soles, and it is even possible that this organism might be made to render the greatest service in marine pisciculture. But it is nevertheless most true that it is in the great variety of plankton organisms that we shall find the food necessary for the normal feeding of the larvæ of teleosts with pelagic eggs. I dared not experiment with purely artificial food, advised by others (cheese, shrimp meal, etc.). I believe that rapid putrefaction would occur. I believe, in short, that during the first period the best food would be small plankton organisms, carefully selected.

Let us add that in hatching troughs the temperature of the water ought not to be above $20^{\circ} \mathrm{C}$. We have operated constantly at a temperature of from $18^{\circ}$ to $20^{\circ} \mathrm{C}$. It seemed best to have it from $15^{\circ}$ to $20^{\circ} \mathrm{C}$. Let us say, further, that during the critical period we lost only 1 individual in IO, a result which might be considered excellent, it seems to me.

What is left to be done in the culture of the turbot? There remains to protect the young larvæ from the end of the critical period to the end of the metamorphosis, since we are sure, and we have often shown by experiment, that there is nothing easier than to fatten young turbots and other pleuronectids, and make them grow. For this purpose it will be sufficient to substitute for the plankton, as rapidly as possible, fish flesh mashed into a pulp, this to be consecutively replaced by larger and larger pieces of fish as the size of the turbots increases.

It remains likewise to carry marine pisciculture from the domain of science to industry, and this is not the least of the work to be done-to determine, in fact, whether the procedure applicable on a small scale in laboratories may be carried on on a larger scale. It is necessary to determine the price of the food required to fatten the fishes bred and to see if this price allows a profit, taking into consideration the market price per kilogram of the turbot.

It is possible that the waste of fishes in the vicinity of great harbors might constitute a valuable resource for industrial marine pisciculture of the future. 


\section{RÉSUMÉ AND CONCLUSION.}

The results obtained by us at the marine laboratory of St. Vaast-la-Hougue during the summer of 1907 are in brief the following:

(I) After Messrs. Malard and Dantan we obtained natural, normal, and abundant hatches of turbot, a result which had been sought for twenty years in a great number of other marine laboratories.

(2) We were the first to succeed in carrying the larvæ of this pleuronectid through the critical period, the obstacle which hitherto all the naturalists studying pisciculture had been unable to overcome, and which seemed to be the principal rock in the course of marine pisciculture.

(3) Throughout our work the mortality of the larvæ may be said to have been a negligible quantity (about Io per cent). 


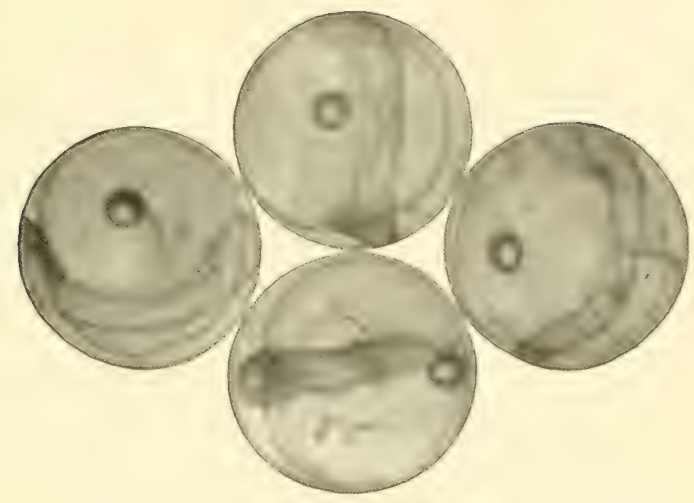

Fis. 1.-Furbot eggs with embryo. Fourth day

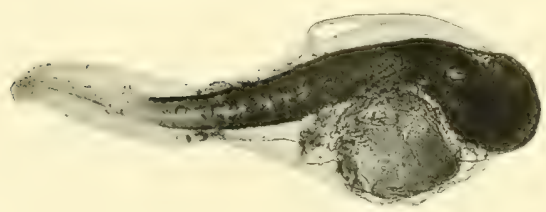

Fic, 2,-Larva with vitellus, Fighth day.

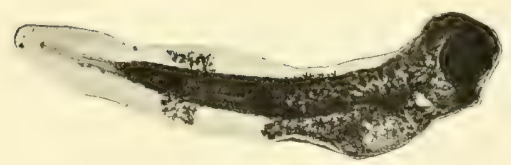

FIG. 3,-I,arva with vitellus almost entirely resorbed-beginning of the critical period. 'Tenth day. 



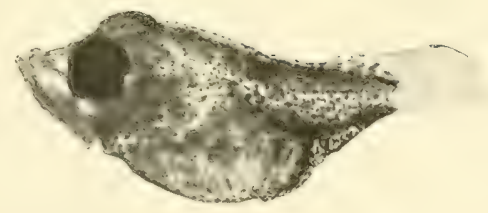

Fic. 4.-Larva a few days after end of critical perioul. Yitellus has disappeated, ahdomen full of food. Shape of fish changed. 'Twenty-thiri day

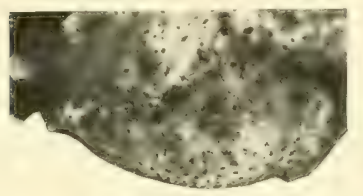

Fis. 5.-Detail of pigmentation of abdomen of ahove figure

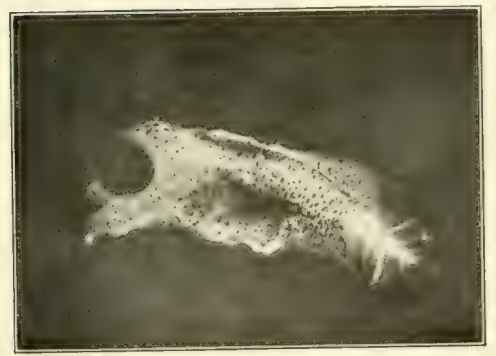

FIG. 6.-Larva after the critical period (cadavious slipe). 




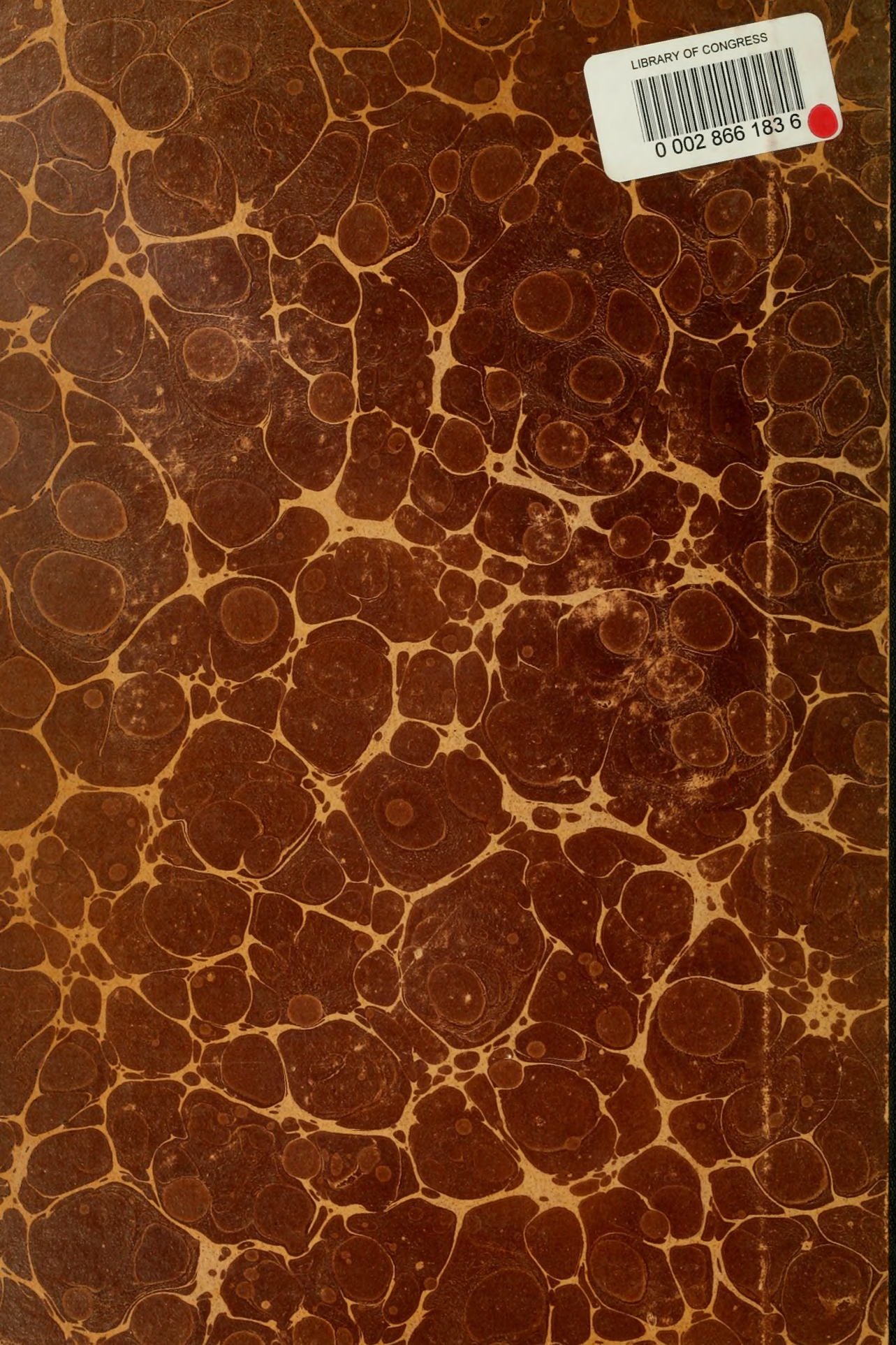

